\title{
SERUM ALANINE AMINOTRANSFERASE (ALT) ACTIVITY AMONG DIABETIC PATIENTS
}

\author{
Anshu Upadhayay* \\ Nepal Institute of Health Sciences, Gokarneshwor, Kathmandu, Nepal \\ *Email: upadhayayanshu@gmail.com
}

\begin{abstract}
Serum Alanine aminotransferase (ALT) activity is the most common screening test as a part of routine assessment of liver damage. Due to its low activity in extra hepatic tissues an increase in serum ALT is more specific for liver disease. The liver pathology among diabetics is similar to that of alcoholic liver disease, including fatty liver, steatohepatitis, fibrosis, and cirrhosis. Thus, elevated serum ALT activity which is a common sign of liver disease is also observed more frequently in diabetics. This study has been designed with the aim to determine the association of serum ALT activity with diabetes mellitus. The study included 208 subjects attending Nepal police hospital during the time frame $6^{\text {th }}$ October 2009 to $4^{\text {th }}$ January 2010 .The ALT activity in serum was determined by kit method, fasting and post prandial sugar was tested by GOD-POD method.

Among the total diabetic subjects $43.26 \%$ were found to have elevated serum ALT activity (>40IU/L). Diabetic status was found to be significantly associated with ALT activity $(\mathrm{p}=0.04)$. In addition to diabetic status body mass index (BMI) was also significantly associated with ALT activity ( $\mathrm{p}=0.02)$ and higher BMI increases the likelihood of elevated ALT. The association of ALT activity was found to be inverse and significant with age of the patient $(\mathrm{r}=-0.217, \mathrm{p}=0.005)$. Physical activity was also found to be inversely associated with ALT activity $(\mathrm{r}=-$ $0.149, \mathrm{p}=0.03)$.
\end{abstract}

Keywords: Alanine aminotransferase; Diabetes; serum glutamate pyruvate transferase; ALT

\section{Introduction}

Alanine aminotransferase (ALT) is a cytoplasmic enzyme; it has an important role in gluconeogenesis and amino acid metabolism. ALT catalyses the transamination reaction of alpha ketoglutarate and L-alanine forming glutamate and pyruvate. The highest ALT activity is found in hepatocytes for this reason it is the most specific marker of liver disease in clinical practice(Stone and Van Thiel, 1985). Increased serum ALT activity can suggest hepatocellular injury or necrosis of striated muscle. In liver disease associated with hepatic necrosis such as viral hepatitis, serum ALT activity is elevated before the clinical signs and symptoms of disease such as jaundice appears.

The liver pathology among diabetics is similar to that of alcoholic liver disease, including fatty liver, steatohepatitis, fibrosis, and cirrhosis (Schindhelm et al., 2006). Thus, elevated serum ALT activity which is a common sign of liver disease is also observed more frequently in diabetics. The relationship between elevated ALT level and Diabetes has been linked with Non-alcoholic fatty liver disease and
Insulin resistance (Banerji et al., 1995). Serum ALT activity which reflect liver fat content, have shown to be associated with diabetes risk, independently of alcohol consumption and other possible factors like high BMI, smoking habit(Sattar et al., 2004). Raised ALT which reflects fatty change in the liver in turn reflects pathophysiological changes predating the development of diabetes. The study has been designed with aim to determine the association of ALT activity with diabetic status and to clarify the factors contributing to ALT elevation. The association may help in management of diabetes and prevent the complication.

\section{Material and Methods}

In this study 208 Patients attending Nepal Police Hospital during the time frame $6^{\text {th }}$ October 2009 to $4^{\text {th }}$ January 2010 were categorized as Diabetic and Non diabetic based on medical records. The information on Tea/coffee consumption, Alcohol intake, smoking status, physical activity and history of Gall stone either present, absent or operated was collected from self-structured questionnaire 
survey. Patients with suspected jaundice were excluded from the study.

The BMI was calculated by measuring the height and weight of each participant and was expressed as $\mathrm{kg} / \mathrm{m}^{2}$. After overnight fasting of 12 hours, $5 \mathrm{ml}$ of blood was collected from each patient by vein-puncture. The separated serum was used for the analysis of Serum Alanine aminotransferase activity, Fasting sugar and post prandial sugar by kit method. Serum ALT activity >40IU/L was considered abnormal. All statistical analysis was performed using SPSS 11 Software. $\mathrm{P}$ value $<0.05$ was considered statistically significant.

\section{Results and Discussion}

The study comprises 208 subjects visiting Nepal police hospital during the time frame $6^{\text {th }}$ October 2009 to 4 th January 2010. Based on the diabetic status subjects were classified as Diabetic and Non -Diabetic. Among the total subjects studied $68 \%$ were diabetic and $32 \%$ were NonDiabetic (Table 1). An elevated ALT is considered a consequence of hepatocyte damage, and is observed more frequently among diabetics (Ruhl et al., 2003;Clark et al., 2003). In the present study among total diabetic subjects 43.26\% were found to have elevated ALT activity (Table 2). Likewise in the study by Arthur and colleagues (Meltzer et al., 1986) ALT activity at least twice the upper limit of normal of 43IU/L was found to be more common among diabetics. Increased gluconeogenesis, owing to increased conversion of alanine to glucose, is suggested as important mechanism for the up regulation of ALT enzyme activity in diabetic subjects (Consoli et al., 1990).

Table 1: Characteristics of study population

\begin{tabular}{lll}
\hline Characteristics & $\begin{array}{l}\text { Diabetic } \\
\text { Mean } \pm \text { S.D }\end{array}$ & $\begin{array}{l}\text { Non } \\
\text { Diabetic } \\
\text { Mean } \pm \text { S.D }\end{array}$ \\
& & $38.25 \pm 12.70$ \\
\hline Age (years) & $53.771 \pm 1.98$ & $24.25 \pm 3.81$ \\
BMI(kg/m2) & $24.61 \pm 3.71$ & $84.29 \pm 9.58$ \\
Fasting sugar(mg/dl) & $133.0 \pm 50.1$ & $102.0 \pm 2.82$ \\
Post prandial & $203.2 \pm 81.34$ & \\
sugar(mg/dl) & & $35.88 \pm 16.87$ \\
Serum ALT & $42.95 \pm 26.73$ & \\
activity(IU/L) & & \\
\hline
\end{tabular}

The mean value of Age, BMI, Fasting sugar, Post prandial sugar and Serum ALT activity in Diabetic and Non diabetic subjects $(n=208)$.

The present finding in accordance with other studies (Vozarova et al., 2002; Hanley et al., 2004; Sattar et al., 2004; Wannamethee et al., 2005) showed a significant association of ALT activity with diabetic status $(\mathrm{p}=0.04)$. The putative role of the liver in the pathogenesis of diabetic mellitus, and impaired hepatic insulin signaling as a consequence of fatty infiltration in the insulin resistant state is posed as an important pathophysiological mechanism for associating ALT activity with diabetes mellitus( Schindhelm et al., 2006).

Table 2: Frequency of elevated ALT in diabetic and NonDiabetic

\begin{tabular}{lll}
\hline $\begin{array}{l}\text { Diabetic } \\
\text { status }\end{array}$ & $\begin{array}{l}\text { No. of } \\
\text { subjects(n) }\end{array}$ & $\begin{array}{l}\text { Elevated ALT } \\
\text { activity n }(\%)\end{array}$ \\
\hline Diabetic & 141 & $61(43.26 \%)$ \\
Non - & 67 & $23(34.3 \%)$ \\
Diabetic & & \\
\hline Among total diabetic subjects $(\mathrm{n}=141)$ & $43.26 \%$ had elevated ALT activity.
\end{tabular}

The study also found a significant inverse co-relation between age and ALT activity ( $\left.\mathrm{r}=-0.217, \mathrm{p}=0.005^{*}\right)$, the mean ALT activity was found to be decreased with increasing age group with peak at 40-59 years of age group in Diabetics (Table 3). Similar co relation between age and ALT activity was reported by previous report, where an inverted $\mathrm{U}$ like relation of ALT and age was revealed (Elinav et al., 2005). Some studies have reported significant association of ALT activity with gender, in the current study a significant difference in ALT activity with gender was found only among Non-Diabetics at $p=0.005$. The mean ALT activity was higher in men than in women among Nondiabetics similar to the study by Leclercq et al. (1999) where the mean ALT activity was higher in men than in women.

Table 3: Co -relation of ALT activity with different parameters

\begin{tabular}{lll}
\hline Parameters & $\begin{array}{l}\text { Pearson co-relation } \\
\text { coefficient (r) }\end{array}$ & P value \\
\hline Age & $-0.217^{*} *$ & 0.005 \\
BMI $(\mathrm{kg} / \mathrm{m} 2)$ & $0.164 *$ & 0.02 \\
Alcohol & 0.007 & 0.19 \\
consumption & & \\
Smoking status & -0.006 & 0.392 \\
Tea / coffee & -0.002 & 0.234 \\
consumption & & \\
$\begin{array}{l}\text { Physical activity } \\
\text { Gall stone }\end{array}$ & $-0.149 *$ & 0.039 \\
$\begin{array}{l}\text { Fasting glucose } \\
\text { level }\end{array}$ & 0.061 & 0.237 \\
$\begin{array}{l}\text { Post prandial } \\
\text { glucose level }\end{array}$ & 0.009 & 0.467 \\
**co relation is significant at 0.01 level $(1$ tailed $)$ & \\
$*$ Co relation is significant at 0.05 level $(1$ tailed $)$ &
\end{tabular}

In accordance with previous studies, the present study found factors in addition to diabetes associated with ALT activity (Table 4).

The majority of previous studies (Sakugawa et al., 2004; Nanji et al., 1986) have shown significant positive association of BMI with ALT. The present result is also in consonance with these studies and a significant positive co relation of ALT activity with BMI was found $\left(\mathrm{r}=0.164^{*}, \mathrm{p}=0.02\right)$. The mean ALT activity was found to be 
increased with degree of obesity. In the analysis of National health and Nutrition examination survey (NHANES) elevated ALT was significantly associated with higher BMI.

Table 4: Association of ALT activity with Diabetic status

\begin{tabular}{lll}
\hline Diabetic status & Mean \pm S.D & P value \\
\hline Diabetic & $42.95 \pm 26.73$ & 0.04 \\
Non - Diabetic & $35.88 \pm 16.87$ &
\end{tabular}

$\overline{\mathrm{ALT}}$ activity was significantly associated with Diabetic status at $\mathrm{p}=0.04$.

Likewise in study by sakaguwa et al(Sakaguwa et al., 2004) the mean ALT activity was found to be increased with degree of obesity. ALT was more clearly related to BMI in the study by Wejstal et al. (1988). Insulin resistance, increased pro-inflammatory cytokine production, Nonalcoholic fatty liver disease, oxidative stress and mitochondrial dysfunction leading to hepatocyte damage/destruction, have all been posed as important pathophysiological mechanism (Schindhelm et al., 2006) causing elevated ALT in obese subjects.

Age and physical activity was negatively co related with ALT at $1 \%$ and $5 \%$ level of significance respectively. BMI was positively co related with ALT at 5\% level of significance. Alcohol consumption, Fasting glucose level, post prandial glucose level, Gall stone showed no significant association with ALT.

The ALT activity was significantly different between the age groups 40-49, 50-59, 60-69 and > 70 in diabetic and Non diabetic subjects. However, the ALT activity was not significantly different within the age groups $(\mathrm{p}=0.172 \& 0.05)$ respectively in diabetic and Non diabetic subjects (Table 5).

Table 5: Age wise comparison of ALT activity

\begin{tabular}{|c|c|c|c|}
\hline $\begin{array}{l}\text { Age group } \\
\text { (years) }\end{array}$ & Diabetic & $\begin{array}{l}\text { Non } \\
\text { Diabetic }\end{array}$ & $\begin{array}{l}P \text { value (t- } \\
\text { test) }\end{array}$ \\
\hline & Mean \pm S.D & Mean \pm S.D & \\
\hline $20-29$ & $41.5 \pm 9.1$ & $29.4 \pm 14.23$ & 0.32 \\
\hline $30-39$ & $48.0 \pm 24.3$ & $37.3 \pm 17.26$ & 0.05 \\
\hline $40-49$ & $50.7 \pm 31.5$ & $41.3 \pm 18.09$ & 0.005 \\
\hline $50-59$ & $42.5 \pm 28.2$ & $25.33 \pm 8.47$ & 0.003 \\
\hline $60-69$ & $36.4 \pm 21.9$ & $28.66 \pm 10.4$ & 0.006 \\
\hline$>70$ & $33.5 \pm 17.6$ & $55.5 \pm 4.94$ & 0.009 \\
\hline
\end{tabular}

The ALT activity was significantly different in Female diabetic and Non diabetic subjects at $\mathrm{p}=0.005$. A significant difference in ALT activity was observed between Male and Female in Non-diabetics $(\mathrm{p}=0.005)$, but not among Diabetics $(\mathrm{p}=0.839)$ (Table 6).
Table 6: Gender wise comparison of ALT activity

\begin{tabular}{llll}
\hline Gender & Diabetic & $\begin{array}{l}\text { Non- } \\
\text { Diabetic }\end{array}$ & $\begin{array}{l}\text { P value } \\
(\mathbf{t}-\text { test })\end{array}$ \\
\hline \multirow{3}{*}{ Male } & Mean \pm S.D & Mean \pm S.D & \\
Female & $42.6 \pm 25.5$ & $38.7 \pm 16.5$ & 0.24 \\
& $43.8 \pm 30.3$ & $25.1 \pm 14.08$ & 0.005 \\
& $\mathrm{P}=0.839$ & $\mathrm{P}=0.005$ & \\
\hline
\end{tabular}

The ALT activity was significantly different in Diabetic and Non diabetic with BMI between $25-30 \mathrm{~kg} / \mathrm{m}^{2}$ at $\mathrm{p}=0.02$. The ALT activity was not significantly different among the age groups ( $\mathrm{p}=0.175 \& 0.25$ ) respectively in diabetic and Non diabetic subjects (Table 7).

Table 7: ALT activity according to BMI grading

\begin{tabular}{llll}
\hline $\begin{array}{l}\text { BMI } \\
\text { grading } \\
\left(\mathbf{k g} / \mathbf{m}^{2}\right)\end{array}$ & Diabetic & $\begin{array}{l}\text { Non } \\
\text { Diabetic }\end{array}$ & $\begin{array}{l}\text { P value } \\
(\mathbf{t}-\text { test }\end{array}$ \\
\hline & & & ) \\
$<25$ & Mean \pm S.D & Mean \pm S.D & \\
$25-30$ & $39.78 \pm 28.57$ & $33.22 \pm 15.92$ & 0.06 \\
$>30$ & $48.34 \pm 23.24$ & $39.65 \pm 17.99$ & 0.02 \\
\hline
\end{tabular}

ALT activity was significantly different in Non-alcoholic, Non-smoker and Tea and coffee consumer Diabetic and Non diabetic subjects with $\mathrm{p}$ value $0.01,0.005$ and 0.03 respectively. ALT activity was significantly different in Non-diabetic Alcoholic and Non Alcoholic subjects (Table 8).

A significant inverse co relation of ALT activity with physical exercise $\left(r=-0.149^{*}, p=0.039\right)$ was found in the present study. Frequency of physical activity was found to be inversely associated with ALT in the study by Debbie et al (Debbie et al., 2005). Few other studies (Suzuki et al., 2005; Hickman et al., 2004) have also postulated an inverse association of ALT with physical activity where the association of ALT with physical activity were based on amount of weight loss and in these studies ALT remained significantly lower in those patients who maintained their reduced weight. Physical activity improves insulin sensitivity and reduces oxidative stress leading to decreased ALT activity.

A non-significant inverse relation between Tea/coffee consumption and ALT activity was found ( $r=-$ $0.002, \mathrm{p}=0.234$ ) which resembles the finding by Meltzer et al(Meltzer et al., 1986) where the risk of elevated ALT activity declined with increasing intake of coffee leading to speculation regarding the possible beneficial effects of $\mathrm{Tea} / \mathrm{coffee}$ on the liver. Coffee consumption was inversely related with serum level of liver enzymes in the study including Japanese men and women (Ikeda et al., 2010). 
Table 8: ALT activity according to Tea Coffee consumption, Smoking status, drinking habit

\begin{tabular}{llll} 
& $\begin{array}{l}\text { Diabetic } \\
\text { Mean } \pm \text { S.D }\end{array}$ & $\begin{array}{l}\text { Non - Diabetic } \\
\text { Mean } \pm \text { S.D }\end{array}$ & P value ( t- test ) \\
\hline Alcoholic & $44.5 \pm 27.4$ & $39.4 \pm 17.2$ & 0.205 \\
Non- Alcoholic & $40.62 \pm 25.7$ & $29.4 \pm 14.3$ & 0.01 \\
& $\mathrm{p}=0.38$ & $\mathrm{p}=0.01$ & 0.906 \\
Smoker & $41.25 \pm 26.07$ & $40.6 \pm 18.1$ & 0.005 \\
Non- Smoker & $44.5 \pm 27.4$ & $33.0 \pm 15.6$ & 0.03 \\
& $\mathrm{p}=0.46$ & $\mathrm{P}=0.08$ & - \\
Tea/ Coffee consumer & $42.7 \pm 27.2$ & $45.3 \pm 18.3$ & $24.0 \pm 0.00$ \\
Tea / Coffee non consumer & $33.0 \pm 15.6$ & - & \\
\hline
\end{tabular}

In the current study, alcohol consumption showed a nonsignificant association with ALT similar to the study performed in Japan (Nakamura et al., 1998; Nakamura et al., 1980). A 4 year follow up study in Korea also demonstrated that the risk for elevated ALT values over the four years increased with the BMI changes (Duk-Hee et al., 2001), but not with alcohol consumption.

In a study by Meltzer (Meltzer et al., 1986) increased alcohol consumption showed positive but not statistically significant association with ALT.

However, in the study on Danish Population as well as a study based on male in London reported the raised level serum liver enzymes with self-reported alcohol consumption(Steffensen et al., 1997; Whitehead et al., 1996). This could be because the total alcohol consumption in our subjects might have been lower than in other studies.

Similarly, presence of Gall stone also showed a nonsignificant association with ALT similar to the study by Arthur et al(Meltzer et al., 1986).

Cigarette smoking may play a role in liver function abnormality and/or specific liver disease. In a on healthy male workers( Chan-Yeung et al., 1981). However, in the current study and similar to another report this correlation was not significant (Jang et al., 2012; Meltzer et al., 1986; Whitehead et al., 1996).

\section{Acknowledgement}

I would like to take this opportunity to acknowledge and offer my deepest gratitude to Biochemistry department of Nepal Police Hospital, Kathmandu, Nepal for granting me the opportunity to conduct this study. I am Grateful to National College for advanced learning, Kathmandu, Nepal for the approval of the study. It is my pleasure to convey my heartfelt admiration to Late Mr. Janardhan Pandey for his valuable suggestions.

\section{Reference}

Banerji MA, Buckley MC, Chaiken RL, Gordon D, Lebovitz HE and Kral JG (1995) Liver fat,serum triglycerides and visceral adipose tissue in insulin-sensitive and insulinresistant black men with NIDDM. Int. J. Obesity Related Metabolic Disorder 19(12): 846-850.

Chan-Yeung M, Ferreira P, Frohlich J, Schulzer M and Tan F (1981). The effects of age, smoking, and alcohol on routine laboratory tests. American Journal of Clinical Pathology 75(3): 320-326. DOI: 10.1093/ajcp/75.3.320

Clark JM, Brancati FL and Diehl AM (2003) The prevalence and etiology of elevated aminotransferase levels in the United States. Am. J. Gastroenterol, 98(5): 71-79. DOI: 10.1111/j.1572-0241.2003.07486.x

Consoli A, Nurjhan N, Reilly JJ Jr, Bier DM and Gerich JE (1990) Mechanism of increased gluconeogenesis in Non-insulin dependent diabetes mellitus.Role of alterations in systemic, hepatic, and muscle lactate and alanine metabolism. The journal of Clinical Investigation 86(6): 2038-2045. DOI: 10.1172/JCI114940

Duk-Hee L, Myung-Hwa Ha and Christiani DC (2001) Body weight, alcohol consumption and liver enzyme activity- a 4-year follow up study. International Journal of Epidemiology 30(4): 766-770.

Elinav E, Ben-Dov IZ, Ackerman E, Kiderman A, Glikberg F, Shapira Y and Ackerman Z (2005) Corelation between serum alanine aminotranferase activity and age: an inverted U curve pattern. Am. J. Gastroenterology 100(10): 2201-2204. DOI: $10.1111 /$ j.15720241.2005.41822.x

Hanley AJ, Williams K, Festa A, Wagenknecht LE, Jr, D'Agostino $\mathrm{RB}, \mathrm{Kempf} \mathrm{J}$ et al. (2004) Elevations in markers of liver injury and risk of Type 2 diabetes: the insulin resistance atherosclerosis study. Diabetes 53(10): 2623-2632. DOI: 10.2337/diabetes.53.10.2623

Hickman IJ, Jonsson JR, Prins JB, Ash S, Purdie DM, Clouston $\mathrm{AD}$ and Powell EE (2004) Modest weight loss and physical activity in overweight patients with chronic liver 
disease results in sustained improvements in alanine aminotransferase, fasting insulin, and quality of life. Gut, 53(3): 413-419. DOI: 10.1136/gut.2003.027581

Ikeda M, Maki T, Yin G, Kawate H, Adachi M, Ohnaka K., ... and Kono S (2010) Relation of coffee consumption and serum liver enzymes in Japanese men and women withy reference to effect modification of alcohol use and body mass index. Scandivarian Journal of Clinical and Laboratory Investigation 70(3): 171-179. DOI: 10.3109/00365511003650165.

Jang ES, Jeong SH, Hwang SH, Kim, HY, Ahn SY, Lee J et al. (2012). Effects of coffee, smoking, and alcohol on liver function tests: a comprehensive cross-sectional study. BMC Gastroenterology 12: 145. DOI: 10.1186/1471230X-12-145

Lawlor DA, Sattar N, Smith GD and Ebrahim S (2005). The associations of Physical activity and Adiposity with Alanine aminotransferase and Gamma Glutamy 1tranferase. American Journal of Epidemiology 161(11): 1081-1088. DOI: 10.1093/aje/kwi125

Leclercq I,Horsmans Y, Bruyere De M and Geubel AP (1999). Influence of Body mass index, sex and age on serum Alanine aminotransferase (ALT) level in healthy blood donars. Acta Gastroenterol Belg. 62(1): 16-20.

Meltzer A, Arthur E and James E (1986). Association between Diabetes and Elevated Alanine Aminotranferase among Mexican Americans. American Journal of Epidemiology 146(7): 565-571. DOI: 10.1093/oxfordjournals.aje.a009315

Nakamura K, Motohashi Y, Kikuchi S, Tanaka M and Nakano S. (1998) Liver transferase activity in healthy Japanese emloyees. Industrial health 36(3): 218-222. DOI: 10.2486/indhealth.36.218

Nakamura S (1980) Alcohol, liver function tests, and high density lipoprotein cholesterol in university students. The Tohoku Journal of Experimental medicine 132(2): 241-242. DOI: $10.1620 /$ tjem.132.241

Nanji AA, French SW and Freeman JB (1986) Serum alanine aminotransferase to aspartate aminotransferase ratio and degree of fatty liver in morbidly obsesses patients. Enzyme 36(4): 266-169.

Ruhl CE and Everhart JE (2003) Determinants of the association of overweight with elevated serum alanine aminotransferase activity in the United States. Gastroenterology 124(1): 71-79. DOI: 10.1053/gast.2003.50004

Sakugawa H, Nakayoshi T, Kobashigawa K, Nakasone H, Kawakami Y, Yamashiro $\mathrm{T}$ et al. (2004) Alanine aminotranferase elevation not associated with fatty liver is frequently seen in obese Japanese women. European Journal of Clinical Nutrition 58(9): 1248-1252. DOI: 10.1038/sj.ejcn.1601956

Sattar N, Scherbakova O, Ford I, O'Reilly DS, Stanley A, Forrest $\mathrm{E}$, et al. (2004) Elevated alanine aminotransferase predicts new onset type 2 diabetes independently of classical risk factors, metabolic syndrome, and $\mathrm{C}$ reactive protein in the west of Scotland coronary prevention study. Diabetes Metabolism Research Revision 53(11): 2855-2860.

Schindhelm RK, Diamant MD, Dekker JM, Tushuizen ME, Teerlink $\mathrm{T}$ and Heine RJ. (2006). Alanine aminotransferase as a marker of non-alcoholic fatty liver disease in relation to Type 2 Diabetes mellitus snd cardiovasculsr disease. Diabetes Metabolism Research Revision 22(6): 437-443. DOI: 10.1002/dmrr.666

Steffensen FH, Sorensen HT, Brock A, Vilstrup H and Lauritzen T (1997) Alcohol consumption and serum liver-derived enzymes in a Danish population aged 30-50 years. International Journal of Epidemiology 26(1): 92-99. DOI: 10.1093/ije/26.1.92

Stone BG and Van Thiel DH (1985) Diabetes Mellitus and the Liver. Semin Liver Disease 5(1): 8-28. DOI: 10.1055/s2008-1041754

Suzuki A, Lindor K, St Saver J, Lymp J, Mendes F, Muto A, et al. (2005) Effect of changes on body weight and lifestyle in nonalcoholic fatty liver disease. Journal of hepatology 43(6): 1060-1066. DOI: 10.1016/j.jhep.2005.06.008

Vozarova B, Stefan N, Lindsay RS, Saremi A, Pratley RE, Bogardus C, Tataranni PA. (2002). High Alanine aminotransferase is associated with decreased hepatic insulin sensitivity and predicts the development of Type 2 diabetes. Diabetes 51(6): 1889-1895. DOI: 10.2337/diabetes.51.6.1889

Wannamethee SG, Shaper AG, Lennon L and Whincup PH (2005) Hepatic enzymes, the metabolic syndrome, and the risk of Type 2 diabetes in older men. Diabetes Care 28(12): 2913 2918. DOI: $10.2337 /$ diacare.28.12.2913

Wejstål R, Hansson G, Lindholm A and Norkrans G (1988) Persistent alanine aminotransferase elevation in healthy swedish blood donars mainly caused by obesity. Vox Sang 55(3): $\quad 152-156 . \quad$ DOI: $\quad 10.1111 / \mathrm{j} .1423-$ 0410.1988.tb05083.x

Whitehead TP, Robinson D and Allaway SL (1996). The Effects of Cigarette Smoking and Alcohol Consumption on Serum Liver Enzyme Activities: A Dose-Related Study in Men. Annals of Clinical Biochemistry 33(6): 530-535. DOI: $10.1177 / 000456329603300607$ 